\title{
Institutional delivery service utilization and associated factors among women of reproductive age in the mobile pastoral community of the Liban District in Guji Zone, Oromia, Southern Ethiopia: a cross sectional study
}

\author{
Wako Golicha Wako ${ }^{1 *}$ (D) and Dejene Hailu Kassa ${ }^{2}$
}

\begin{abstract}
Background: Globally, an estimated 289,000 maternal deaths occurred in 2013. Majority of these deaths occurred in sub-Saharan Africa and Southern Asia. Mobility of pastoralists is a well-recognized survival strategy in arid and semi-arid land of sub-Saharan Africa. However governments often encourage settlement as a solution to the difficulty of providing health services for mobile pastoralists. This study aimed to assess utilization of institutional delivery and associated factors among women of reproductive age in the mobile pastoral community of the Liban District in Guji zone, Oromia, Ethiopia.

Methods: A Community based cross-sectional survey was conducted among the mobile pastoralist community of the Liban District. Seven hundred ninety-one (791) randomly selected women, who had birth within the last 2 years preceding the survey, were interviewed using a pretested structured questionnaire. Data were entered into Epi-Info version 3.5.4 and analyzed by Statistical Package for Social Science (SPSS) version 16. Bivariate and multivariate analyses were done.

Results: Out of 791 women who gave birth within the last 2 years preceding the survey, only 110 (13.9\%) gave birth in health institutions. Majority (74.1\%) of the women gave birth at their home. Ninety-one women (11.5\%) gave birth at traditional birth attendant's home; assisted by traditional birth attendants. Multiple logistic regression shows that women who had readily available cash at the onset of labor (aOR 2.79, 95\% Cl: 1.29-6.25), delivered the birth preceding the most recent birth in a health institution (aOR 6.8, 95\% Cl: 3.44-13.45) and had birth related complications during the birth preceding the most recent birth (aOR 1.90, 95\% Cl: 1.08-3.36) were more likely to deliver at health institutions.
\end{abstract}

Conclusion: Majority of the pastoral women seek institutional delivery, only when labor related complications are perceived. Mechanisms of alleviating indirect health care costs affecting institutional delivery need to be addressed in future studies.

Keywords: Institutional delivery, Mobile pastoralists, Indirect health care cost

\footnotetext{
* Correspondence: bwakot730@gmail.com

${ }^{1}$ Wolkite University College of Medicine and Health Sciences, Welkite,

Ethiopia

Full list of author information is available at the end of the article
} 


\section{Background}

At the beginning of this century, 189 member states of United Nations endorsed a millennium declaration and committed themselves to eight Millennium Development Goals (MDGs) to improve the living standards of citizens worldwide [1]. Two of these goals were to reduce child mortality (MDG 4) and maternal mortality (MDG 5) [1]. By the end of 2015 some of these MDGs like poverty reduction and primary education for all were achieved. However achieving MDG 4 and MDG 5 were failed especially in sub-Saharan Africa [2].

Globally, it was estimated that 289,000 maternal deaths occurred in 2013 [3]. This indicates a 45\% reduction from the baseline of 1990 [3]. According to the 2013 World Health Organization (WHO) report, maternal deaths are highest in sub-Saharan Africa and Southern Asia. Sixty two (62\%) percent of global maternal deaths took place in sub-Saharan Africa alone, followed by southern Asia (24\%) [3]. Ethiopia is among countries with highest maternal mortality ratio (MMR) in the world with an estimated MMR of 676/ 100,000 live births [4].

In the past century, pastoral zones have been neglected by governments in terms of social services provision including health care. Geographical dispersion and mobility of pastoralists would create significant barriers to health service delivery, including institutional delivery. Governments often encourage settlement as a solution to the difficulty of providing health services for mobile pastoralists [5]. Mobility of pastoralists, however, is a well-recognized survival strategy in arid and semiarid lands of sub-Saharan Africa. Moreover mobility is very critical for the livestock survival and, the livelihoods and survival of the pastoralists [6].

Many studies explored health institutional delivery utilization and its predictors in most socio-economic settings of Ethiopia. Few efforts, however, have been made to study this in a pastoral community. Therefore, this study aimed to assess the utilization of institutional delivery and associated factors among women of reproductive age in the mobile pastoral community of the Liban District in Guji Zone, Oromia.

\section{Methods}

\section{Study setting}

The study was conducted in the Liban District of Guji Zone, State of Oromia, Southern Ethiopia. The district is located in the lowlands of southern Ethiopia approximately 925 meters above sea level. The district's administrative town, Nagelle Borana is located $595 \mathrm{~km}$ south of Addis Ababa, Ethiopia's capital. The district is predominantly inhabited by the Borana agro-pastoral and pastoral community. Among the inhabitants are mobile pastoralists whose lifestyle is characterized by seasonal mobility for wise management of scarce water and pasture for a livestock.

\section{Study design and population}

A community based cross-sectional survey was conducted among women of reproductive age who had given birth within the last 2 years preceding the survey. The study was conducted in the area of the district considered to host mobile pastoralists.

\section{Sample size and sampling procedures}

The report of 2014 Ethiopian mini Demographic and Health Survey (EDHS) was used to estimate sample size for the first objective. According to the report 10.4\% of rural women delivered in health institutions [7]. Considering 95\% confidence level and 3\% absolute precision; the minimum required sample size was calculated as following:- $\mathrm{n}=\left(\mathrm{z}_{1} \alpha / 2\right){ }^{2 *} \mathrm{p}(1-\mathrm{p}) / d^{2}$; were: $\mathrm{z}_{1-\alpha} \alpha / 2=\mathrm{z}$-score corresponding to $95 \%$ confidence interval, which is 1.96 ; $\mathrm{p}$ - is anticipated sample proportion, which is $10.4 \%$ and $\mathrm{d}$ - is an absolute precision, which is $3 \%$. Accordingly the minimum required sample size was 398. Sample size for the second objective was calculated by Epi-info7 statCalc software. Three independent variables were considered for the sample sizes calculation. The sample sizes were calculated with common assumptions of: Power of $80 \%$; two sided confidence level of $95 \%$ and ratio of control to case of 1. Finally the largest sample size among four sample sizes was used for the study. Therefore sample size for the first objective (i.e. $\mathrm{n}=398$ ) was used, because it is the largest one. Because participants' selection was not done by direct simple random sampling method, the design effect of 2 was considered. Additionally, 10\% non-response rate was considered. Final sample size required was: $398 * 2+0.1(398 * 2) \approx 876$.

\section{Sampling procedures}

The area of the district which hosts majority of the mobile pastoralists is found to one side of the district. This side of the district was considered as one geographical area. The geographical area is formed by four different kebeles. The Sample size was allocated to the kebeles proportional to the approximate number of households. Each kebele was further subdivided into smaller administrative units called "Gare". Finally, the sample size taken from each "Gare" was allocated proportional to the number of households in the "Gare". In each "Gare" eligible women were enumerated and participants were selected by systematic random sampling. The whole process of approximating households, allocating sample sizes to each kebele and "Gare", selecting the participants and data collection was accomplished within three weeks to reduce effects of mobility on the study. 


\section{Data collection}

Data was collected by a pretested structured questionnaire. An English language questionnaire was developed by authors after reviewing relevant literatures. Finalized version of the questionnaire was translated into local language (i.e. Afan Oromo). The Afan Oromo questionnaire was pretested in nearby pastoral kebele not participating into the study. The Afan Oromo questionnaire was used to collect data. Informed verbal consent to participate was obtained from participants. Verbal consent was preferred over written consent, because majority of participants were non-literate women.

\section{Data analysis}

The data were entered into Epi-Info version 3.5.4, cleaned and analyzed with SPSS version 16. Frequency distributions were run and the prevalence of institutional delivery utilization was estimated. Bivariate analysis was done for all independent variables. $P<0.1$ on bivariate analysis was used as a cutoff point to select the independent variables for multivariate analysis. Adjusted odds ratio with 95\% confidence interval $(\mathrm{CI})$ and $P<0.05$ was used to declare statistical significance.

\section{Results}

\section{Socio-demographic characteristics of the respondents}

Out of the total 876 reproductive age women planned for the study, 791 women were successfully interviewed and included into final analysis (response rate 90.3\%). Two questionnaires were excluded from analysis because of major incompleteness of the collected data. Eighty three (83) women were not found after frequent home visits. The mean $( \pm \mathrm{SD})$ age of the respondents was 28.1 $( \pm 7)$ years. Majority of women were non-literate of any language (92.7\%) and the rest (7.3\%) were literate. Waqefata was dominant religion $(59.3 \%)$ followed by Islam (32.5\%) and Protestantism (8.2\%). Majority of women were housewife (Table 1).

Approximately one third of the women owned ten or more "Hawicha" of cattle and $12 \%$ of the women owned ten or more "Hawicha" of camel. Table 2 shows details of household livestock ownership status.

\section{Past obstetric history}

Majority of the respondents, 724 (91.5\%) were women who had more than one birth. Two hundred and twenty eight $(31.5 \%)$ of women who had had more than one birth, reported complications during the birth preceding the most recent one. The most frequently reported complication was long duration of labor (see Table 3).
Table 1 Socio-demographic characteristics of the respondents, Liban District, Oromia; Southern Ethiopia; June 2015

\begin{tabular}{lll}
\hline Characteristics of respondents & Frequency & percentage \\
\hline Age of women in completed year & & \\
$<=19$ & 89 & 11.3 \\
$20-34$ & 521 & 65.9 \\
$>=35$ & 181 & 22.9 \\
Total & 791 & 100.0 \\
Husbands' educational level & & \\
No education(grade 0) & 575 & 83.7 \\
Primary education(grade 1-8) & 94 & 13.7 \\
Secondary education and above & 18 & 2.6 \\
( grade 9 and above ) & & 100.0 \\
Total & 687 & \\
Women's occupation & & 98.0 \\
House wife & 775 & 2.0 \\
Others & 16 & 100.0 \\
Total & 791 & \\
Family size & & 7.5 \\
$<=4$ & 163 & 20.6 \\
5-6 & 176 & 51.6 \\
> =7 & 452 & 100.0 \\
Total & 791.0 \\
Months elapsed since last mobility by households & \\
$<=5$ months & 59 & \\
Total & & \\
\hline
\end{tabular}

Knowledge and attitude of respondents towards maternal health services

Majority of women knew that government health institutions provide delivery service (92.7\%). They knew about availability of free obstetric ambulance at Woreda health office $(93.2 \%)$ and delivery services are provided free of charge at the government health institutions (90.1\%).

\section{Institutional delivery utilization}

Out of 791 women who gave birth within the last 2 years preceding the survey, only $110(13.9 \%)$ gave birth in health institutions and the remaining 681 (86.1\%) gave birth elsewhere. Among women who gave birth at the health institutions, only $30(27.3 \%)$ had planned to give birth at a health institution. The remaining 80 (72.7\%) gave birth at the health institutions because of labor related complications. Ninety-one (11.5\%) of women gave birth at traditional birth attendants' home and assisted by traditional birth attendants. Two hundred eighty six (36.2\%) births were attended by traditional birth 
Table 2 Livestock ownership by households, Liban District, Oromia, southern Ethiopia, June 2015

\begin{tabular}{lll}
\hline Types of livestock & Frequency & Percentage \\
\hline Cattle owned in "Hawicha" & & \\
$<=4$ & 243 & 30.7 \\
$5-9$ & 300 & 37.9 \\
$>=10$ & 248 & 31.4 \\
Total & 791 & 100.0 \\
Camel owned in "Hawicha" & & \\
$<=4$ & 459 & 58.0 \\
$5-9$ & 237 & 30.0 \\
$>=10$ & 95 & 12.0 \\
Total & 791 & 100.0 \\
Goat and Sheep owned in " Hawicha" & & \\
$<=10$ & 386 & 48.8 \\
$11-20$ & 309 & 39.1 \\
$>=21$ & 96 & 12.1 \\
Total & 791 & 100.0 \\
\hline
\end{tabular}

a "Hawicha"- is the local livestock counting mechanism, in which only animals which had at least one birth are counted

attendants, irrespective of place of delivery. Deliveries attended by skilled personnel were $102(12.9 \%)$. One hundred seventeen $(22.4 \%)$ women reported complications during labor and/or delivery of the most recent birth. The most frequently reported complication was prolonged duration of labor (Table 4).

When labor of the most recent birth started, 415 $(52.5 \%)$ women had readily available cash. The remaining 335 (42.4\%) women did not have readily available cash.

\section{Factors associated with institutional delivery}

Odds ratios from multiple logistic regression show that women who had readily available cash when labor started (aOR 2.79, 95\% CI:1.29-6.25), delivered the child preceding the most recent one in a health institution (aOR 6.8, 95\% CI:3.44-13.45)and faced birth related complications during the birth preceding the most recent one (aOR 1.90, 95\% CI:1.08-3.36) were more likely to deliver at a health institution. Utilization of institutional delivery among non-literate women was not different from literate women (aOR 0.92, 95\% CI: 0.273.11). Institutional delivery utilization by women not in marital union was not different from those married (aOR 0.67, 95\% CI: 0.24-1.57). Extent of household mobility, distance to road and health institution and perceived availability of transportation had no association with institutional delivery.

Radio listening frequency did not significantly affect the place of delivery. The utilization of institutional delivery among women who do not listen to radio at all
Table 3 Past obstetric history of respondents, Liban District, Oromia; southern Ethiopia, June 2015

\begin{tabular}{lll}
\hline Past obstetric history & Frequency & Percentage \\
\hline Number of previous birth & 67 & 8.5 \\
1 & 273 & 34.5 \\
$2-4$ & 451 & 57.0 \\
$>=5$ & 791 & 100.0 \\
Total & & \\
Place of the birth preceding the & & \\
most recent one & 516 & 71.3 \\
Home & 92 & 12.7 \\
Traditional birth attendant's home & 8 & 1.1 \\
Health post & 88 & 12.2 \\
Health center & 19 & 2.6 \\
Hospital & 1 & 0.1 \\
Others & 724 & 100.0 \\
Total & & \\
Presence of complication during the birth & & \\
preceding the most recent one & 496 & 68.5 \\
No & 228 & 31.5 \\
Yes & 724 & 100.0 \\
Total &
\end{tabular}

Type of complication encountered during birth preceding the most recent one $e^{a}$

\begin{tabular}{lll} 
Prolonged labor & 126 & 50.4 \\
Excessive vaginal bleeding & 30 & 12.0 \\
Still birth & 47 & 18.8 \\
convulsion & 43 & 17.2 \\
Others & 4 & 1.6 \\
Total & 250 & 100.0 \\
\hline
\end{tabular}

${ }^{a}$ : multiple responses are possible

was not significantly different from those who listen to radio sometimes (aOR 1.33, 95\% CI: $0.67-2.61$ ) and most of the time (aOR 1.02, 95\% CI: 0.36-2.93) (Table 5).

Most obstetric characteristics of women had no association with institutional delivery, except the place of the birth preceding the most recent one and presence of complications during the birth preceding the most recent one (Table 6).

\section{Discussion}

The prevalence of institutional delivery in this study was $13.9 \%$ (95\% CI: $11.5-16.3 \%)$. Women who had readily available cash when labor onset, delivered the birth preceding the most recent one in a health institution and faced birth related complications during the birth preceding the most recent one were more likely to have institutional delivery.

Prevalence of institutional delivery in this study is similar with a study in Banja District, Amhara regional 
Table 4 Characteristics of the most recent birth, Liban District, Oromia, Southern Ethiopia, June 2015

\begin{tabular}{|c|c|c|}
\hline Characteristics of most recent birth & Frequency & Percentage \\
\hline \multicolumn{3}{|l|}{ Place of the most recent birth } \\
\hline Home & 586 & 74.1 \\
\hline Traditional birth attendant's home & 91 & 11.5 \\
\hline Health post & 10 & 1.3 \\
\hline Health center & 75 & 9.5 \\
\hline Hospital & 25 & 3.2 \\
\hline Others & 4 & 0.5 \\
\hline Total & 791 & 100.0 \\
\hline \multicolumn{3}{|l|}{ Who attended the most recent birth } \\
\hline Relative & 297 & 37.5 \\
\hline Traditional birth attendant & 286 & 36.2 \\
\hline Health extension worker & 10 & 1.3 \\
\hline Midwife/doctor/nurse/health officer & 102 & 12.9 \\
\hline Nobody & 96 & 12.1 \\
\hline Total & 791 & 100.0 \\
\hline \multicolumn{3}{|l|}{$\begin{array}{l}\text { Type of complications faced during } \\
\text { the most recent birth }\end{array}$} \\
\hline Prolonged labor & 105 & 53.6 \\
\hline Excessive vaginal bleeding & 29 & 14.8 \\
\hline Still birth & 23 & 11.7 \\
\hline Convulsion & 32 & 16.3 \\
\hline Others & 7 & 3.6 \\
\hline Total & 196 & 100.0 \\
\hline \multicolumn{3}{|l|}{$\begin{array}{l}\text { Reasons for not delivering the most } \\
\text { recent birth at a health institution }{ }^{\mathrm{a}}\end{array}$} \\
\hline Facility too far/no transportation & 355 & 43.7 \\
\hline Not customary & 315 & 38.7 \\
\hline Do not know the existence of service & 41 & 5.0 \\
\hline Do not trust health worker & 41 & 5.0 \\
\hline Not necessary & 17 & 2.1 \\
\hline Facility not open & 14 & 1.7 \\
\hline No female provider & 3 & 0.4 \\
\hline Others & 27 & 3.3 \\
\hline Total & 813 & 100.0 \\
\hline
\end{tabular}

${ }^{a}$ : multiple responses are possible

state of Ethiopia. In Banja District, $15.7 \%$ of women delivered in health institutions [8]. However, the prevalence in this study is much lower than the prevalence in Goba Woreda of Oromia regional state among urban and rural women where 47\% (95\% CI: 42.9-51.1\%) delivered in health institutions [9]. In Ethiopia, evidences show that prevalence of institutional delivery among rural women is lower than among urban women [4, 7]. The current study shows lower prevalence of institutional delivery compared to the study in Goba Woreda, probably because of inclusion of urban women in the later. In addition to rural-urban difference, the difference in institutional delivery may be due to difference in socio-economic settings. Pastoral communities have limited access to social service infrastructures, including health care [5]. The limited access to health care might influence utilization of institutional delivery. However, the prevalence in the current study is a bit higher than the national rural average of institutional delivery in Ethiopia [7]. Mini Ethiopian Demographic and Health survey of 2014(EDHS 2014), reported that 10.4\% (95\% CI: $9.6-11.2 \%)$ of rural women gave their most recent birth in a health institution [7].

Women who had readily available cash at the time of labor onset were almost three times more likely to deliver at a health institution compared to those who did not have cash. Though delivery services are free of charge at government health institutions; indirect health care costs may be a barrier. Ninety percent of women who gave birth at the health institutions delivered at health centers or hospitals. Almost all of these health institutions are found at more or less urban areas, whether it is a small rural or urban town. Moving to such health institutions may demands rural women and/or accompanying persons to have at least some money to cover essential expenses like food. In pastoral communities, however, money consists of livestock, which might be difficult to sell any time unlike other assets. First, market centers where livestock are to be sold might be located far away at urban areas, requiring a long distance drive with their livestock to the market centers. Second, despite the distant market centers, market days are limited within a given week. In the study area, for instance there are only 2 market days per week. Third, because livestock are highly valued and major income resources, its sell may require discussion among family members. All these three above conditions make livestock an unreliable source of money during emergencies of a woman in labor, unless livestock is sold prior to onset of labor. This may be further evidenced by the fact that livestock possessions did not affect institutional delivery. This study did not assess birth preparedness and complications readiness, which includes capital preparation. A study in Goba Woreda showed that women who were birth prepared and had complication readiness were more likely to deliver at health institutions.

Provided that delivery services are given free of charge for all women, the current findings support the importance of indirect health care costs on institutional delivery. Work done in five low income countries showed that even in the presence of fee waiver and exemption systems women continue to pay for maternal health services, a large proportion of which is informal payments [10]. The same work demonstrated that fee waiver and exemption 
Table 5 Socio-demographic factors associated with institutional delivery, results from logistic regressions, Liban District, Oromia, Southern Ethiopia, June 2015

\begin{tabular}{|c|c|c|c|c|}
\hline \multirow[t]{2}{*}{ Factors } & \multicolumn{2}{|c|}{ Institutional delivery } & \multirow[t]{2}{*}{ Crude odds ratio } & \multirow[t]{2}{*}{ Adjusted odds ratio $(95 \% \mathrm{Cl})$} \\
\hline & No (\%) & Yes (\%) & & \\
\hline \multicolumn{5}{|l|}{ Women age } \\
\hline$<=19$ & $81(91.0)$ & $8(9.0)$ & 1.00 & NA \\
\hline $20-34$ & $452(86.8)$ & $69(13.2)$ & 1.56 & NA \\
\hline$>=35$ & $148(81.8)$ & $33(18.2)$ & 2.26 & NA \\
\hline Total & 681 & 110 & & \\
\hline \multicolumn{5}{|l|}{ Religion } \\
\hline Waqefata & $404(86.1)$ & $65(13.9)$ & 1.00 & NA \\
\hline Islam & $219(85.2)$ & $38(14.8)$ & 1.08 & NA \\
\hline Protestant & $58(89.2)$ & $7(10.8)$ & 0.75 & NA \\
\hline Total & 681 & 110 & & \\
\hline \multicolumn{5}{|c|}{ Women educational status } \\
\hline Non-literate & 631 & 102 & 1.00 & NA \\
\hline Literate & 50 & 8 & 0.99 & NA \\
\hline Total & 681 & 110 & & \\
\hline \multicolumn{5}{|l|}{ Women marital status } \\
\hline Not in marital union & 81 & 23 & 1.00 & NA \\
\hline Married & 600 & 87 & 0.51 & NA \\
\hline Total & 681 & 110 & & \\
\hline \multicolumn{5}{|c|}{ Months elapsed since last mobility by household } \\
\hline$<=5$ months & 53 & 6 & 1.00 & NA \\
\hline $6-59$ months & 344 & 64 & 1.64 & NA \\
\hline$>=60$ months & 284 & 40 & 1.24 & NA \\
\hline Total & 681 & 110 & & \\
\hline \multicolumn{5}{|c|}{ Time taken to reach nearest functional transport road } \\
\hline$<=$ one hour & 455 & 96 & 1.00 & 1.00 \\
\hline$>$ one hour & 226 & 14 & 0.29 & $0.45(0.16,1.26)$ \\
\hline Total & 681 & 110 & & \\
\hline \multicolumn{5}{|c|}{ Time taken to reach nearest health facility } \\
\hline$<=2$ hours & 169 & 12 & 1.00 & 1.00 \\
\hline $3-5$ hours & 454 & 79 & 2.45 & $1.23(0.47,3.22)$ \\
\hline 6 hours & 68 & 19 & 4.61 & $2.26(0.68,7.56)$ \\
\hline Total & 681 & 110 & & \\
\hline \multicolumn{5}{|c|}{ Perceived availability of transportation when labor started } \\
\hline No & 386 & 54 & 1.00 & 1.00 \\
\hline Yes & 295 & 56 & 1.38 & $0.58(0.32,1.05)$ \\
\hline Total & 681 & 110 & & \\
\hline \multicolumn{5}{|l|}{ Radio listening frequency } \\
\hline Not at all & 389 & 49 & 1.00 & 1.00 \\
\hline Sometimes & 227 & 51 & 1.78 & $1.33(0.67,2.61)$ \\
\hline Most of time & 65 & 10 & 1.22 & $1.02(0.36,2.93)$ \\
\hline Total & 681 & 110 & & \\
\hline
\end{tabular}


Table 5 Socio-demographic factors associated with institutional delivery, results from logistic regressions, Liban District, Oromia, Southern Ethiopia, June 2015 (Continued)

\begin{tabular}{|c|c|c|c|c|}
\hline \multicolumn{5}{|l|}{ Cattle owned in "Hawicha" } \\
\hline$<=4$ & $217(89.3)$ & $26(10.7)$ & 1.00 & 1.00 \\
\hline $5-9$ & $246(82)$ & $54(18)$ & 1.83 & $1.23(0.60,2.53)$ \\
\hline$>=10$ & $218(87.9)$ & $30(12.1)$ & 1.15 & $1.24(0.53,2.88)$ \\
\hline Total & 681 & 110 & & \\
\hline \multicolumn{5}{|l|}{ Camel owned in "Hawicha" } \\
\hline$<=4$ & $407(88.7)$ & $52(11.3)$ & 1.00 & 1.00 \\
\hline $5-9$ & $189(79.7)$ & $48(20.3)$ & 1.99 & $1.53(0.80,2.91)$ \\
\hline$>=10$ & $85(89.5)$ & $10(10.5)$ & 0.92 & $1.38(0.49,3.89)$ \\
\hline Total & 681 & 110 & & \\
\hline \multicolumn{5}{|c|}{ Goat and sheep owned in "Hawicha" } \\
\hline$<=10$ & $340(88.1)$ & $46(11.9)$ & 1.00 & NA \\
\hline $11-20$ & $259(83.7)$ & $50(16.3)$ & 1.43 & NA \\
\hline$>=21$ & $82(85.4)$ & $14(14.6)$ & 1.26 & NA \\
\hline Total & 681 & 110 & & \\
\hline \multicolumn{5}{|c|}{ Readily available cash when labor started } \\
\hline No & $316(94.3)$ & $19(5.7)$ & 1.00 & 1.00 \\
\hline Yes & $332(80.0)$ & $83(20.0)$ & 4.16 & $2.79(1.25,6.25)^{*}$ \\
\hline Others $^{\mathrm{a}}$ & $33(80.5)$ & $8(19.5)$ & 4.03 & $5.57(1.53,20.32)^{*}$ \\
\hline Total & 681 & 110 & & \\
\hline \multicolumn{5}{|l|}{ Husband's education } \\
\hline No education & $502(87.3)$ & $73(12.7)$ & 1.00 & NA \\
\hline Primary education and above & $98(87.5)$ & $14(12.5)$ & 0.98 & NA \\
\hline Total & 600 & 87 & & \\
\hline \multicolumn{5}{|l|}{ Family size } \\
\hline$<=4$ & $146(89.6)$ & $17(10.4)$ & 1.00 & NA \\
\hline $5-6$ & $153(86.9)$ & $23(13.1)$ & 1.29 & NA \\
\hline$>=7$ & $382(84.5)$ & $70(15.5)$ & 1.58 & NA \\
\hline Total & 681 & 110 & & \\
\hline \multicolumn{5}{|c|}{ Decision maker for institutional delivery } \\
\hline Husband and wife jointly & 581 (86.6) & 90 (13.4) & 1.00 & 1.00 \\
\hline Mainly wife & $57(75.0)$ & $19(25.0)$ & 0.46 & $(0.47,12.66)$ \\
\hline Total & 638 & 109 & & \\
\hline
\end{tabular}

NA not applicable

*: the test was significant at $p-<0.05$

a: either "I do not know" or "I do not remember"

mechanisms will not alleviate the burden of out of pocket costs, because more than $80 \%$ of out of pocket costs for maternal health services are informal costs. Poor clients do not benefit from government fee subsidies because of poor awareness of fee waiver and exemption mechanisms [10]. In the current study, majority (84.2\%) of the women had good knowledge of delivery service including free ambulance service and free delivery services at government health institutions. However, institutional delivery was not significantly different between women who had unfavorable and favorable attitudes towards institutional delivery.

The women who delivered the birth preceding the most recent birth at health institutions were almost seven times more likely to deliver at health institutions than those who delivered such birth elsewhere. The finding is in line with a study in Banja District of Amhara regional state, Ethiopia [8]. This may due to the fact that women who delivered at health institutions may better appreciate the advantages of 
Table 6 Obstetric and related factors associated with institutional delivery, results from logistic regressions, Liban District, Oromia, Southern Ethiopia, June 2015

\begin{tabular}{|c|c|c|c|c|}
\hline \multirow[t]{2}{*}{ Factors } & \multicolumn{2}{|c|}{ Institutional delivery } & \multirow[t]{2}{*}{ Crude odds ratio } & \multirow[t]{2}{*}{ Adjusted odds ratio $(95 \% \mathrm{Cl})$} \\
\hline & No (\%) & Yes (\%) & & \\
\hline \multicolumn{5}{|l|}{ Parity } \\
\hline$<4$ & $210(89.0)$ & $26(11.0)$ & 1.00 & NA \\
\hline$>=4$ & $471(84.9)$ & $84(15.1)$ & 1.44 & NA \\
\hline Total & 681 & 110 & & \\
\hline \multicolumn{5}{|c|}{ ANC during pregnancy of the most recent birth } \\
\hline No & $237(87.4)$ & $34(12.6)$ & 1.00 & NA \\
\hline Yes & $444(85.4)$ & $76(14.6)$ & 1.19 & NA \\
\hline Total & 681 & 110 & & \\
\hline \multicolumn{5}{|c|}{ Place of birth preceding the most recent birth } \\
\hline Not health institution & $561(92.1)$ & $48(7.9)$ & 1.00 & 1.00 \\
\hline Health institution & $59(51.3)$ & $56(48.7)$ & 11.09 & $6.80(3.44,13.50)^{*}$ \\
\hline Total & 620 & 104 & & \\
\hline \multicolumn{5}{|c|}{$\begin{array}{l}\text { Presence of complication during birth preceding } \\
\text { the most recent birth }\end{array}$} \\
\hline No & $461(92.9)$ & $35(7.1)$ & 1.00 & 1.00 \\
\hline Yes & $159(69.7)$ & $69(30.3)$ & 5.72 & $1.90(1.08,3.36)^{*}$ \\
\hline Total & 620 & 104 & & \\
\hline \multicolumn{5}{|c|}{$\begin{array}{l}\text { Willingness to deliver at facility where male } \\
\text { provides service }\end{array}$} \\
\hline No & $157(94.6)$ & $9(5.4)$ & 1.00 & 1.00 \\
\hline Yes, if no option & $171(85.5)$ & $29(14.5)$ & 2.96 & $1.44(0.45,4.66)$ \\
\hline Yes, no problem & $352(83.0)$ & $72(17.0)$ & 3.57 & $2.25(0.75,6.72)$ \\
\hline Total & 680 & 110 & & \\
\hline \multicolumn{5}{|c|}{ Attitudes towards institutional delivery } \\
\hline Unfavorable & $362(89.2)$ & $44(10.8)$ & 1.00 & NA \\
\hline Favorable & 319 (82.9) & $66(17.1)$ & 1.72 & NA \\
\hline Total & 681 & 110 & & \\
\hline
\end{tabular}

NA not applicable

*: the test was significant at $p<0.05$

institutional delivery, and this may encourage seeking health institutional delivery for subsequent deliveries.

The women who had complications during the birth preceding the most recent birth were more likely to deliver in health institutions. This finding is similar to a study in northern Ethiopia, which showed that women who had a history of obstetric complications tend to deliver at health institutions [11]. Also in current study, the majority of the women who delivered at the health institutions did so because of the complications they faced during labor. Among women who gave the most recent birth at the health institutions, only about $27.3 \%$ of them had planned to give birth at a health institution. The rest delivered at the health institutions because of perceived complications during labor.
Socio-demographic characteristics of women like age, literacy, religion and family size did not seem to affect the place of delivery. Place of delivery was not associated with current maternal age, consistent with a study in northern Ethiopia [11]. But it is inconsistent with many others which reported current maternal age as the factor affecting place of delivery $[4,7,8]$. Contrary to many studies, the current study reported that women's literacy status did not an have association with place of delivery $[7-9,11,12]$. Consistent with many other studies, the current study reported that decision maker $[8,9,11]$, husbands' education [11] and habit of listening radio $[8,9,11]$ ' did not significantly influence the choice of place of childbirth. Even though pastoral mobility was claimed as one cause of the difficulty in providing health care to pastoralists, the current study did not 
show a significant association between extent of household mobility and the place of childbirth. Similarly, distance to the nearest health institution and functional transport road were not associated with the place of childbirth. Similar findings were reported in a study from Goba Woreda [9]. However, $51.1 \%$ of the women who delivered outside health institutions mentioned lack of transportation and/or distance to health institution as one of the reasons for not delivering in a health institution.

Unlike many studies $[7,9,12]$, antenatal care utilization was not associated with place of delivery in the current study. Also marital status and parity were not associated with the place of birth. These findings are consistent with studies done in Gondar and Goba, Ethiopia $[9,11]$. In this study, the area of the district that considered hosting the mobile pastoralist and housing characteristics were criteria to distinguish mobile from settled pastoralists. But these criteria are not perfect in distinguishing the two from each other. So, chance of including some settled pastoral women in the study is possible. Therefore, this should be taken into account while interpreting the study.

\section{Conclusion}

Majority of the pastoral women seek institutional delivery, only when labor related complications are perceived. Women should be educated to seek institutional delivery for all births. Mechanisms of alleviating indirect health care costs affecting institutional delivery need to be addressed in future studies.

\section{Additional file}

Additional file 1: Questionnaire. Title of data: English language questionnaire for study entitled "Institutional delivery service utilization and associated factors among women of reproductive age in the mobile pastoral community of the Liban District in Guji Zone, Oromia, southern Ethiopia: A cross sectional study". Description of data: the questionnaire used to collect data for the study. (DOCX $20 \mathrm{~kb}$ )

\section{Abbreviations}

ANC: Antenatal care; aOR: Adjusted odds ratio; Cl: Confidence interval; CSA: Central statistical agency; EDHS: Ethiopian Demographic and Health Survey; FIGO: International Federation of Gynecology and Obstetrics; HIV/ AIDS: Human immunodeficiency virus/Acquired immunodeficiency syndrome; ICM: International Confederation of Midwives; MDGs: Millennium development goals; MOFED: Ministry of Finance and Economic

Development; UN: United Nations; WHO: World Health Organization

\section{Acknowledgements}

We would like to express our deepest gratitude and appreciation to Hawassa University College of Medicine and Health Sciences for financially supporting the study. We are grateful to Guji Zone and Liban Woreda Health Office for the permission to undertake the study. Our honest gratitude also goes to all data collectors and supervisors for their commitment and hardship resiliency. Lastly, but not the least, we would like to extend our thanks to those study participants who volunteered to participate.

\section{Funding}

This research was financed by Hawassa University College of Medicine and Health sciences. The funder did not have any role in design of the study, data collection, analysis, interpretation, writing manuscript and decision to publish.

\section{Availability of data and materials}

Full data set and other materials pertaining to this study can be obtained from corresponding author on reasonable request. Questionnaire used in this study has been attached as Additional file 1 .

\section{Authors' contributions}

WG conceived the project, developed proposal, did data analysis and interpretation and wrote the manuscript. DH developed proposal, did data analysis and interpretation and wrote the manuscript. Both authors read and approved the final manuscript.

\section{Authors' information}

Wako Golicha (MPH): is lecturer at Wolkite University College of Medicine and Health Sciences, Ethiopia.

Dejene Hailu (M. Phil, PhD): is assistant professor at Hawassa University

College of Medicine and Health Sciences, Ethiopia.

\section{Competing interest}

The authors declare that they have no competing interests.

\section{Consent for publication}

Not applicable.

\section{Ethics approval and consent to participate}

Ethical clearance was obtained from institutional review board of Hawassa University College of Medicine and Health Sciences and; informed verbal consent was obtained from each participant during data collection. Confidentiality of the information was secured by omitting personal modifiers on the questionnaire. The consent to participate statement read as "Hello. My name is and we are conducting a household survey about various health issues related to giving child birth in health facilities. The survey is conducted for purpose of master thesis work by student from Hawassa University. We are interviewing women on issues related to their household, past obstetrics history and use of health facilities for child birth. I want to interview you on aforementioned issues. We would very much appreciate your participation in this survey. This information will be used only for master thesis work. The survey usually takes not more than 15 min to complete. Whatever information you provide will be kept strictly confidential, and will not be shared with anyone other than members of our survey team and your name will not be written on this paper. Participation in this survey is voluntary, and if we should come to any question you don't want to answer, just let me know and I will go on to the next question; or you can stop the interview at any time. However, we hope you will participate in the survey since your views are important. At this time, do you want to ask me anything about the survey? May I begin the interview now? 1. Respondent agrees to be interviewedstart interview

2. Respondent does not agree to be interviewed —____ _ end"

\section{Publisher's Note}

Springer Nature remains neutral with regard to jurisdictional claims in published maps and institutional affiliations.

\section{Author details}

${ }^{1}$ Wolkite University College of Medicine and Health Sciences, Welkite, Ethiopia. ${ }^{2}$ Hawassa University College of Medicine and Health Sciences, Awasa, Ethiopia

Received: 15 October 2015 Accepted: 8 May 2017

Published online: 15 May 2017

\section{References}

1. United Nations. United Nations Millennium Declaration; 8th plenary meeting. New York: UN; 2000. available at:https://www.un.org/press/en/ 2000/20000908.ga9758.doc.html. 
2. United Nations. The Millennium Development Goals Report. New York: United Nations; 2014.

3. WHO, UNICEF, UNFPA, World Bank, United Nations population Division. Trends in Maternal Mortality: 1990 to 2013. Geneva: World Health Organization; 2013.

4. Central Statistical Agency[Ethiopia] and ICF International. EthiopiaDemographic and Health Survey2011. Addis Ababa and Calverton: Central statistical Agency and ICF International; 2012.

5. Schelling E, Weibel D, Bonfoh B. Learning from the Delivery of Social Services to Pastoralists: Elements of good practice. Nairobi: Intenational Union for Conservation of Nature(IUCN); 2008.

6. Leloup S. Investing in Maintaining Mobility in Pastoral Systems of the Arid and Semi-Arid Regions of Sub-Saharan Africa:An ALive Policy Note. Partnership for Livestock Development, Poverty Alleviation and Sustainable Growth. 2006. Available at:http://www.fao.org/fileadmin/templates/lead/pdf/ e-conf_06-10_mobility.pdf.

7. Central Statistical Agency [Ethiopia]. Ethiopia Mini Demographic and Health Survey 2014. Addis Ababa: Central Statistical Agency; 2014.

8. Wolelie A, Achiluhm M, Awoke W. Institutional delivery service utilization and associated factors in Banja District, Awie Zone, Amhara Regional Sate, Ethiopia. Open J Epidemiol. 2014;4:30-5. Available at: http://dx.doi.org/10. 4236/ojepi.2014.41006.

9. Bogale D, Markos D. Institutional delivery service utilization and associated factors among child bearing age women in Goba Woreda, Ethiopia. J Gynecol Obstet. 2014;2:63-70.

10. Sharma S, Smith S, Sonneveldt E, Pine M, Dayaratna V, Sanders R. Formal and informal fees for maternal health care services in five countries: policies, practices and perspectives. USAID, 2005 Contract No.:16. http://www. policyproject.com/pubs/workingpapers/WPS16.pdf.

11. Nigussie M, Hailemariam D, Mitike G. Assessment of safe delivery service utilization among women of childbearing age in north Gondar Zone, north west Ethiopia. Ethiop J Health Dev. 2004;18(3):145-52. available at: http://dx. doi.org/10.4314/ejhd.v18i3.9952.

12. Getachew M, Negash K, Yesouf J, Melese M. Determinants of delivery practices among Afar pastoralists of Ethiopia. Pan Afr Med J. 2012;13(supp1): 17. available at: https://www.ncbi.nlm.nih.gov/pmc/articles/PMC3587020/.

\section{Submit your next manuscript to BioMed Central and we will help you at every step:}

- We accept pre-submission inquiries

- Our selector tool helps you to find the most relevant journal

- We provide round the clock customer support

- Convenient online submission

- Thorough peer review

- Inclusion in PubMed and all major indexing services

- Maximum visibility for your research

Submit your manuscript at www.biomedcentral.com/submit

) Biomed Central 